\title{
Acute respiratory tract infection among preschool children in Western Maharashtra, India
}

\author{
Mahesh B. Tondare', V.V. Raje ${ }^{2}$, Sachin Mumbare', M.V. Rayate', Sangamesh Tondare ${ }^{3}$, S.V. Kakade ${ }^{4}$ \\ ${ }^{1}$ Deptartment of Community Medicine, Ashwini Rural Medical College, Kumbhari, Solapur, Maharashtra, India, ${ }^{2}$ Deptartment of Community \\ Medicine, Krishna Institute of Medical Sciences, Karad Satara, Maharashtra, India, ${ }^{3}$ Deptartment of Surgery, Sri Devaraj Urs Medical College, \\ Kolar, Karnataka India, ${ }^{4}$ Department of Community Medicine, Krishna Institute of Medical Sciences, Karad Satara, Maharashtra
}

\section{A B S T R A C T}

Background: Malnutrition and infectious diseases both occur in the same unfortunate children and together they play a major role in causing the high morbidity and mortality in them. In developing countries, mortality from ARTI is 30-70 times higher than in developed countries and it has been estimated that up to $1 / 3^{\text {rd }}$ of all deaths in children less than 5 years are attributed to ARTI. Aims \& Objectives: This study aimed to find the attack rate of Acute Respiratory Tract infection and the socio-demographic variables of pre-school children suffering from Acute Respiratory Tract infections. Method: A Comparative Longitudinal study was carried out among preschool children (3-5 years) who were selected from Private pre-primary school of urban area (155)\& Anganwadis (157) of urban slum area of karad town and followed for the period of one year. Mother/guardian/teacher was interviewed by using pre-tested proforma during this period. Results \& Interpretation: out of all $97.4 \%$ of private pre-primary school children had 1.8 episodes/child/year of ARTI compared to Anganwadi children where all of them had 2.5 episodes/child/year of ARTI. Conclusion: Maximum number of children from private pre-primary schools from urban area also suffered with at least one episode of Acute Respiratory Tract Infection compared to Anganwadi children from urban slum areas.
Access this article online Website:

http://nepjol.info/index.php/AJMS

Key words: Anganwadi, ARTI, Incidence, Maternal literacy, Pre-primary school children

\section{INTRODUCTION}

Malnutrition and infectious diseases both occur in the same unfortunate children and together they play a major role in causing the high morbidity and mortality in them. ${ }^{1}$ The period below 5 years among the children is the most crucial period and if any infection occurs during this period, will affect the growth and development of child because maximum growth and development occur in this period. Among the infectious diseases, Acute Respiratory Tract Infections (ARTI) and acute diarrhoeal disease (ADD) are leading cause for childhood mortality and morbidity. ${ }^{2}$ In developing countries, mortality from ARTI is $30-70$ times higher than in developed countries and it has been estimated that up to $1 / 3^{\text {rd }}$ of all deaths in children less than 5 years are attributed to ARTI. ${ }^{3}$ In India ARTI is one of the major cause of death and it is also one of the major reason for which children are brought to hospitals and health facilities. ${ }^{4}$

ARTI is responsible for 30-50\% OPD attendance, 20-40\% hospital admission, and it was observed that every child below 5 years of age suffer about 5 episodes of ARTI per year, thus accounting for about 238 million attacks every year and 1-2 lack deaths annually and among that $90 \%$ deaths were below the age of 5 years. ${ }^{5}$ According to the Director General's published figures, these account for $15-20 \%$ mortality during this age group. The current estimates of about 600,000 annual deaths during pre-school age group are realistic. The case fatality rate is high and ranging, between 5-10\%. ${ }^{5}$ According to NFHS II (1998-99), ${ }^{6}$ prevalence of ARTI in children below 3 years of age in India was $19.3 \%$, out of which $64 \%$ of ARTI cases were taken to health facility or a health care providers. 
The incidence of ARTI in Maharashtra is 3.67 per child per year. $^{7}$

\section{MATERIAL AND METHODS}

A Community Based Comparative Longitudinal Study was conducted in urban area among the pre-primary school children, 3-5 years at the time of selection of study subjects from two different sectors of the community i.e. Private \& Government (Anganwadis) for comparison. The services provided in the setup \& the socio-economic status of family is different in these two sectors so hence were selected for comparison.

Sample size was calculated by taking the incidence of Acute Respiratory Tract Infection from the past study i.e. $11 \%(\mathrm{p}){ }^{7}$ and considering 5\% error (E), which comes around 151 . The formula applied was sample size $=(1.96)^{2} \times \mathrm{pq} / \mathrm{E}^{2}$. Considering the chances of drop outs during the Course of the study, extra $10 \%$ samples were added it. So the final sample size was 166 . This sample was taken from private pre-primary school and similar number of samples was also taken from anganwadi centres. Three Private pre-primary school \& four Anganwadi centres from karad city were enrolled randomly to reach the desired number of children. The child who was present for all the visits was included in the study whereas those children who missed one or more visits were excluded from the study.

Children \& their mother/guardian/teacher were enrolled for the study by using pre strutchered \& pretested proforma. The proforma included the baseline data i.e. general particulars of the parents and children and also on birth and immunization history (cross checked from records), breastfeeding history and anthropometric measurements of the child; general and systemic examination of each subject was carried out. The information was collected from mother/father/guardian and class teacher/anganwadi worker. During this period, parents were told about the signs and symptoms of Acute Respiratory Tract Infections so that they can deliver proper history.

Baseline data was collected in the month of January 2010. Subsequent three follow up visits were carried out at the interval of every 3 months i.e. in the month of April-May, August-Sept \& December-January. During the follow up visits, episodes were counted if they appeared freshly after completion of previous visit \& during the visit. This procedure was repeated for all the follow ups. During these visits, history of any illnesses including episodes of ARTI till the follow up visit was collected from the mother, guardian or class teacher/anganwadi worker followed by General and systemic examination of the child.

Institutional Ethics Committee clearance and informed verbal consent from the parents/guardians/principals/ Child Development Project Officer (CDPO) was obtained prior to the study. All the data collected were entered in to Excel sheet and analysed for frequency, percentage, Chi-square test, Odds ratio.

\section{OBSERVATIONS}

In this study total 312 children were followed up (155 from private pre-primary schools and 157 from anganwadis), excluding 20 dropouts. During the course of one year follow up, it was observed that, the overall episodes of ARTI were 686, with attack rate of 98.71 \& incidence 2.198 episodes per child per year.

Incidence \& attack rate was calculated as follows;

Incidence rate (spells $)^{8}=$ number of spells of sickness starting in a defined period $\times 1000 /$ number of persons exposed to risk in that period.

Attack rate ${ }^{8}=$ number of new cases of a specified disease during specified time interval $\times 100 /$ total population at risk during same interval.

Among private pre-primary children followed for one year 151 out of 155 had attack of ARTI one or more time giving an incidence rate of 1.89 episodes/child/year (attack rate 97.4\%) compared to anganwadi children who had an attack rate of $100 \%$ \& Incidence rate of 2.5 episodes/child/year (Table1).

The incidence of ARTI was observed higher among the boys of private pre-primary school children whereas

\begin{tabular}{|c|c|c|c|c|c|c|}
\hline Group & No. & $\begin{array}{l}\text { No. of children } \\
\text { affected }\end{array}$ & $\begin{array}{c}\text { Total } \\
\text { episodes }\end{array}$ & $\begin{array}{l}\text { Episodes/ } \\
\text { child/year }\end{array}$ & $\begin{array}{l}\text { Attack } \\
\text { rate } \%\end{array}$ & Incidence \\
\hline $\begin{array}{l}\text { Private pre primary } \\
\text { school children }\end{array}$ & 155 & 151 & 293 & 1.890 & 97.41 & 1890 \\
\hline Boys & 83 & 81 & 159 & 1.195 & 97.59 & 1915 \\
\hline Girls & 72 & 70 & 134 & 1.861 & 97.22 & 1861 \\
\hline Anganwadi children & 157 & 157 & 393 & 2.503 & 100 & 2503 \\
\hline Boys & 98 & 98 & 237 & 2.418 & 100 & 2418 \\
\hline Girls & 59 & 59 & 156 & 2.689 & 100 & 2689 \\
\hline
\end{tabular}


reverse finding was observed among Anganwadi children. These findings were not found statistically significant.

From the Table 2, the period prevalence of ARTI combined (PVT and anganwadi) was 58.6\% during the baseline data collection period which increased in $1^{\text {st }}$ and $3^{\text {rd }}$ visits, with mean episodes/child of $(0.631 \pm 0.483$ and $0.621 \pm 0.485)$ respectively.

Significantly High proportion of ARTI affected children from private pre-primary school (46.4\%) and anganwadi (70.7\%) had past history of ARTI $\left(\boldsymbol{\chi}^{2}=18.82, \mathrm{p}=0.000\right)$.

Figure 1 shows the percentage of episodes of ARTI attacks among pre-primary school children, according to which maximum number of children $(>50 \%)$ had nearly 2-3 episodes per year in both private as well as anganwadis
ARTI was seen more among boys \& the children of age group 48-60months but it was not found statistically significant. Significantly more numbers of children affected with ARTI were staying in either joint family or three generation family among both the groups. Significantly maximum proportions of ARTI affected children were belonging to either upper or middle socio-economic class among private school children whereas among anganawadi children they belong to lower socio-economic class (Table 3).

Significantly more numbers of ARTI affected children from Anganwadi were born with more than second order and birth weight less than $2.5 \mathrm{kgs}$. Most of the mothers of these children were illiterate and were working by occupation compared to private school children \& their mothers. Also significantly more numbers of Anganwadi children were not exclusively breast fed, not breast fed for $>2$ yrs and

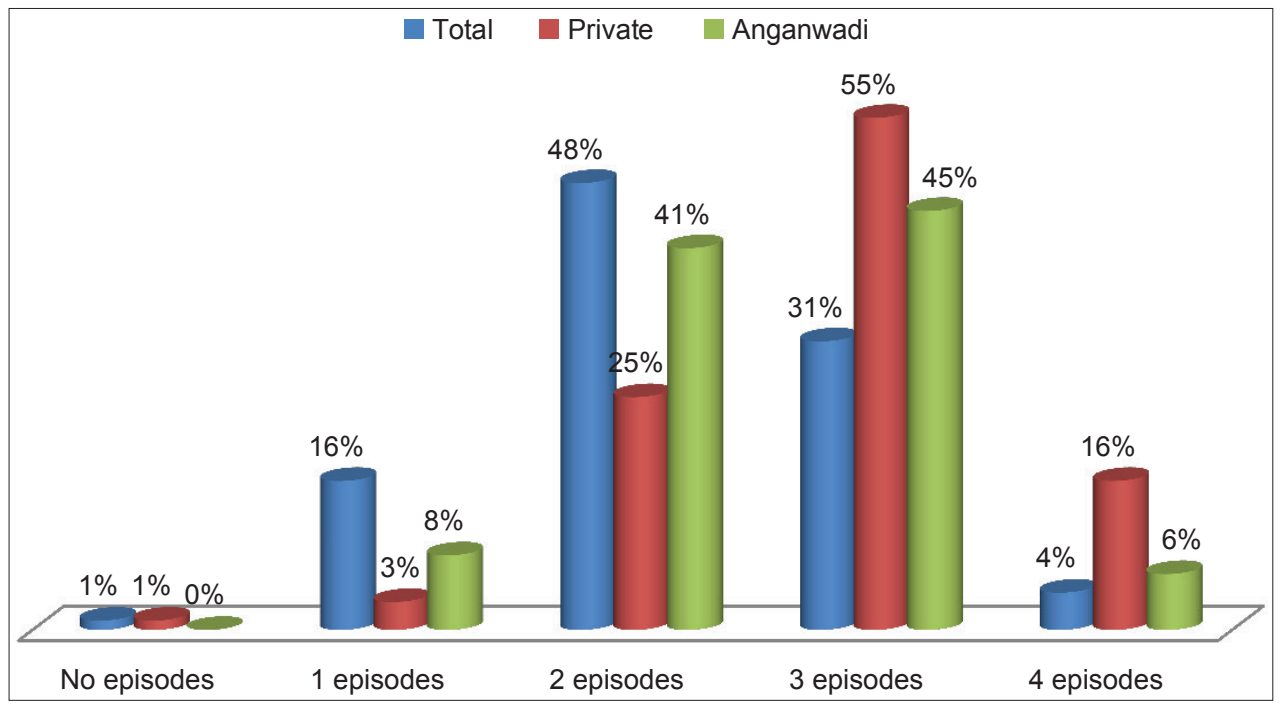

Figure 1: ARTI episodes among pre-primary school children private pre-primary school \& Anganwadi children

\begin{tabular}{|c|c|c|c|c|}
\hline Particulars & $\begin{array}{c}1^{\text {st }} \text { contact }\left(1^{\text {st }} \text { Dec } 2009\right. \\
\left.\text { to } 31^{\text {st }} \operatorname{Dec} 2009\right)\end{array}$ & $\begin{array}{l}\text { Visit I (1st Jan } 2010 \\
\text { to } 30^{\text {th }} \text { April 2010) }\end{array}$ & $\begin{array}{l}\text { Visit II (1 } 1^{\text {st }} \text { May } 2010 \\
\text { to } 31^{\text {st }} \text { Aug 2010) }\end{array}$ & $\begin{array}{l}\text { Visit III (1 } 1^{\text {st }} \text { Sept } 2010 \\
\text { to } 31^{\text {st }} \text { Dec 2010) }\end{array}$ \\
\hline \multicolumn{5}{|l|}{ Total episodes } \\
\hline Combined (Pvt\&AW) & 183 & 197 & 112 & 194 \\
\hline Private & 98 & 83 & 33 & 79 \\
\hline Anganwadi & 85 & 114 & 79 & 115 \\
\hline \multicolumn{5}{|l|}{ Mean episodes/child } \\
\hline Combined (Pvt\&AW) & 0.586 & 0.631 & 0.359 & 0.621 \\
\hline Private & 0.632 & 0.535 & 0.212 & 0.509 \\
\hline Anganwadi & 0.541 & 0.726 & 0.503 & 0.732 \\
\hline \multicolumn{5}{|l|}{ Standard deviation } \\
\hline Combined (Pvt\&AW) & 0.493 & 0.483 & 0.480 & 0.485 \\
\hline Private & 0.483 & 0.500 & 0.410 & 0.501 \\
\hline Anganwadi & 0.499 & 0.447 & 0.501 & 0.444 \\
\hline \multicolumn{5}{|l|}{ Period prevalence } \\
\hline Combined (Pvt\&AW) & $58.6 \%$ & $63.1 \%$ & $35.8 \%$ & $62.1 \%$ \\
\hline Private & $63.2 \%$ & $53.5 \%$ & $21.2 \%$ & $50.9 \%$ \\
\hline Anganwadi & $54.1 \%$ & $72.6 \%$ & $50.3 \%$ & $73.2 \%$ \\
\hline
\end{tabular}


weaning started before 6 months compared to private school children (Table 4).

On application of Odds ratio among children of private primary school children showed significant difference between children suffering \& not suffering from ARTI with respect to mother's occupation \& Education, Birth weight $\&$ birth order, exclusive breast feeding, total breast feeding $\&$ age at start of weaning. Chances of development of ARTI among private pre primary school children was 20.5 times more among non exclusive breast fed, 29.2 times more among not totally Breast fed children, 19.6 times more among early start of weaning \& 14 times more among

\begin{tabular}{|c|c|c|c|}
\hline Particulars & $\begin{array}{c}\text { PVT (\%) } \\
n=151\end{array}$ & $\begin{array}{l}\text { Anganwadi } \\
(\%) n=157\end{array}$ & $\begin{array}{l}\chi^{2} \text { value } \\
\text { ( } p \text { value })\end{array}$ \\
\hline \multicolumn{4}{|l|}{ Sex of the child } \\
\hline Boys & $81(53.6)$ & $98(62.4)$ & 2.089 \\
\hline Girls & $70(46.4)$ & $59(37.6)$ & $(0.148)$ \\
\hline \multicolumn{4}{|l|}{ Age group (mn) } \\
\hline $36-47$ & $48(31)$ & $59(37.6)$ & 1.234 \\
\hline $48-60$ & $107(69)$ & $98(62.4)$ & $(0.266)$ \\
\hline \multicolumn{4}{|l|}{ Type of family } \\
\hline Nuclear & $87(57.6)$ & $75(47.8)$ & 34.62 \\
\hline Joint & 27 (17.9) & $71(45.2)$ & $(0.001)^{*}$ \\
\hline Three generation & $37(24.5)$ & $11(07)$ & \\
\hline \multicolumn{4}{|c|}{ Socio economic status } \\
\hline Upper & $38(25.1)$ & $02(1.4)$ & 151.3 \\
\hline Middle & $80(53.1)$ & $12(7.6)$ & $(0.001)^{*}$ \\
\hline Lower & $33(21.8)$ & $143(91)$ & \\
\hline
\end{tabular}

*highly significant

\begin{tabular}{|c|c|c|c|}
\hline Particulars & $\begin{array}{c}\text { PVT (\%) } \\
n=151\end{array}$ & $\begin{array}{l}\text { Anganwadi } \\
\text { (\%) } n=157\end{array}$ & $\begin{array}{l}\chi^{2} \text { value } \\
\text { ( } p \text { value) }\end{array}$ \\
\hline \multicolumn{4}{|l|}{ Maternal Education } \\
\hline Illiterate & $00(00)$ & $94(59.5)$ & 127.3 \\
\hline Literate & $151(100)$ & $63(40.1)$ & $(0.001)^{*}$ \\
\hline \multicolumn{4}{|l|}{ Maternal Occupation } \\
\hline Working Mothers & $05(3.3)$ & $134(85.4)$ & 205.9 \\
\hline Non-working Mothers & $146(96.7)$ & $23(14.6)$ & $(0.001)^{*}$ \\
\hline \multicolumn{4}{|l|}{ Birth Weight } \\
\hline$<2.5 \mathrm{Kgs}$ & $04(2.6)$ & $28(17.8)$ & 17.46 \\
\hline$\geq 2.5 \mathrm{Kgs}$ & $147(87.4)$ & $129(82.2)$ & $(0.001)^{*}$ \\
\hline \multicolumn{4}{|l|}{ Birth order } \\
\hline$\leq 2$ & $141(93.4)$ & $106(67.5)$ & 30.80 \\
\hline$>2$ & $10(6.6)$ & $51(32.5)$ & $(0.001)^{*}$ \\
\hline \multicolumn{4}{|l|}{ Exclusive breast feeding } \\
\hline Present & $144(95.4)$ & $47(29.9)$ & 137.1 \\
\hline Absent & $07(4.6)$ & $110(70.1)$ & $(0.001)^{*}$ \\
\hline \multicolumn{4}{|l|}{ Total breast feedings } \\
\hline Up to $2 \mathrm{yrs}$ & $146(96.7)$ & $147(93.6)$ & 1.554 \\
\hline$>2$ yrs & $05(3.3)$ & $10(6.4)$ & $(0.296)^{*}$ \\
\hline \multicolumn{4}{|l|}{ Weaning } \\
\hline$\leq 6$ months & $131(86.8)$ & $97(61.8)$ & 23.6 \\
\hline$>6$ months & $20(13.2)$ & $60(38.2)$ & $(0.001)^{*}$ \\
\hline
\end{tabular}

children with birth order 2 or more. Whereas occurrence of ARTI could be decreased by 2.1 times if birth weight is more than or equal to $2.5 \mathrm{kgs}, 3$ times if mother is not working \& 0.3 times if mother is educated. Odds ratio could not be applied to the other group i.e. Anganwadi children as all of them were suffering from ARTI.

\section{DISCUSSION}

As we know that the incidence of ARTI is very much higher in under five children, the number of factors that can make difference in occurrence of these diseases vary in various geographical areas, according to change in socioeconomic status and various environmental factors, which was studied in the current study among the pre-school age children of urban (private pre-primary school) and urban slum (anganwadi) \& observed that the incidence of ARTI was very much higher among the anganwadi children (2.5 episodes/child/year) than the private pre-primary school children. Which is almost equal to the incidence reported by various community based studies from different parts of India by Kabra SK et $\mathrm{al}^{7}$, the incidence of ADD found by Gupta N et al ${ }^{9}$ was 1.69 episodes/child/year, which was more than the present study in private pre-primary school children, which may reflect the better environmental condition.

In the current study maximum ARTI affected children were boys, which is almost similar to the findings of Savitha MR et $\mathrm{al}^{10}$, Kazi Md. Abul Kalam Azad ${ }^{11}$, Pore PD et al ${ }^{12}$ in which the male affected population was almost $2 / 3^{\text {rd }}$ of the total and reverse findings were found in the study of Prajapati Bipin et $\mathrm{al}^{13}$ because boys are biologically weaker than girls. Pore PD et $\mathrm{al}^{12}$ and Meriton Stanly et $\mathrm{al}^{14}$ (41\%, 52\% and $47.5 \%$ respectively), of ARTI affected children were between the age group of 25-60 months, in comparison to the present study more than $60 \%$ of the ARTI affected children from both pre-primary schools were between the age group of 48-60 months.

Significantly higher proportion of illiterate mothers were observed among ARTI affected children from anganwadi, similar findings was observed by Kazi Md. Abul Kalam Azad $^{11}$, Savitha MR et $\mathrm{al}^{10}$ and Pore PD et all ${ }^{12}$, it is known that the female literacy is less in urban slum and which is always associated with health ignorance, poor hygiene, which may reflect the health status of children.

Maximum ARTI affected children from both the groups stayed in the nuclear family $(57.5 \%$ in private pre-primary school and 48\% in anganwadi) and the result obtained was statistically significant, similar findings were observed in semi urban area, Gujarat by Bhanderi D et al ${ }^{15}$, it is the disadvantage of the nuclear family in taking care of the sick children due to the lack of man power and support to 
the mother. Around 90\% of ARTI affected children from anganwadi were from low socio economic class (Class IV and V), whereas study conducted in Bangladesh by Kazi Md. Abul Kalam Azad ${ }^{11}$ found $48 \%$ of affected children belong to low socio economic class, this might be due to the combined effect of poor maternal education and low socio economic status.

Significantly higher proportion of ARTI affected children from anganwadi $(32.5 \%)$ were of birth order $>2$, as compared to the affected children from private pre-primary school (6.6\%), similarly in a community based study done by Mitra NK ${ }^{16} 43 \%$ of affected cases of ARTI were also of birth order more than 2, as it was observed that as the birth order increases the risk to various other infections.

The proportion of ARTI was seen higher in anganwadi children with birth weight less than $2.5 \mathrm{kgs}$, in comparison with the children of private pre-primary school, similar finding was observed by where as $80 \%$ of the LBW children had suffered by ARTI which was observed by Shah HK et al ${ }^{17}$ in her community based study in Goa, lower the birth weight lower the immunity which increase the chances of infections.

In the present study $71 \%$ of the ARTI affected children from anganwadi had positive past history of ARTI, in comparison with $46 \%$ of ARTI affected children from private pre-primary schools. Similarly Dudley et a ${ }^{18}$, Pritsch Silvio O.M et al ${ }^{19}$ also observed positive past history for $>50 \%$ children who are affected by ARTI.

\section{CONCLUSION}

Maximum number of children from private pre-primary schools suffered with at least one attack of Acute Respiratory Tract Infection. Maternal illiteracy and working mothers found favourable factors in causing ARTI. Immunization coverage, EBF and proper weaning play a very important role in prevention of infections in early life as well as repeated attacks in future.

\section{REFERENCES}

1. Walter James J. Longitudinal study of the morbidity of diarrhoeal and respiratory infections in malnourished children. The American journal of Clinical nutrition 1972; 25:690-694.
2. Ian M. Aetiology of Acute Respiratory Tract infections in children in Rural Community in the Gambia, The Paediatric Infectious disease journal 1992; 11:466-473.

3. Ghai OP: Text book of Essential Paediatrics, 2004, $6^{\text {th }}$ edition, CBS Publications \& distributions Pvt. Ltd: 269-280.

4. Acute Respiratory Tract Infections in Children: Case management in small hospitals in developing countries, A Manual for Doctors and other Senior Health workers, WHO. Geneva, Dec 1994.

5. WHO (1995), the world Health report 1995, bridging the gaps, Report of the Director- General.

6. NFHS II (1998-99), International Institute for Population Sciences, Deonar, Mumbai.

7. Kabra SK, Lodha R. Acute respiratory mortality. Background papers 19-22.

8. Park K. Text book of Preventive \& Social Medicine. Chapter 3 - Principles of Epidemiology \& Epidemiological Methods. $21^{\text {st }}$ edition: p.no. 57.

9. Gupta N, Jain SK, Ratnesh, Chawla U, Hossain S and S.Venkatesh. An Evaluation of Diarrhoeal diseases and Acute Respiratory Tract Infections control Programmes in a Delhi Slum. Indian Journal of Paediatrics 2007; 74:471-476.

10. Savitha MR, Nandeeshwara MJ, Kumar P, Farhan-ul-haque and Raju CK. Modifiable risk factors for Acute Lower Respiratory tract infections. Indian Journal of Pediatrics 2007; 74.

11. Kazi Md and Azad Abul Kalam. Risk Factors for Acute Respiratory Tract Infections (ARTI) Among Children under Five Years in Bangladesh. Journal of scientific research J.Sci.Res 2009; 1 (1):72-81.

12. Pore PD, Ghattargi $\mathrm{CH}$ and Rayate MV. Study of risk factors of Acute Respiratory Tract Infection in underfives in Solapur. National Journal of Community Medicine 2010; 1 (2): 64-67.

13. Bipin P, Nitiben T and Sonaliya KN. A Study on Prevalence of Acute respiratory Tract infections (ARTI) in under five children in Urban \& rural communities of Ahmedabad District, Gujrath. National Journal of Community Medicine 2011; 2 (2).

14. Stanly M, Sathiyasekaran BWC and Palanis G. A Population Based Study of Acute Diarrhoea among Children under 5 years in a Rural Community in South India. Sri Ramachandra Journal of Medicine 2009; 1 (1):1-7.

15. Bhanderi $D$ and Choudary SK. An epidemiological study of health and nutritional status of under five children in semi-urban community of Gujarat. Indian Journal of Public Health 2006; 50(4):213-9.

16. Mitra NK. A Longitudinal Study on ARTI among Rural Under Five. IJCM 2001; 26 (1):3-48.

17. Shah HK. A longitudinal study of Acute Respiratory Tract Infections in the under five age group in a rural area of Goa. Indian Journal of Community Medicine 1998; XXIII, No 3.

18. Dudley L, Hussey G, Huskissen J and Kessow G. Vitamin A status, other risk factors and Acute Respiratory Tract Infection morbidity in children. SAMJ 1997; 87 (1):65-70.

19. Prietsch Silvo OM. Acute lower respiratory illness in under five children in Rio Grande, Rio Grande do Sul State, Brazil: prevalence and risk factors. Cad. Saude Publica, Rio de Janerio 2008; 24 (6):1429-1438.

\footnotetext{
Authors Contribution:

MBT - Design, Data Collection, Follow-up, Data entry, Data Analysis, Manuscript Preparation \& Correspondence; VVR - Concept, Design, Data Analysis, Manuscript Editing; SM - Manuscript Review; MVR - Manuscript Review; SBT - Manuscript Preparation; SVK - Statistical analysis.
}

Source of Support: Nil, Conflict of Interest: None declared. 